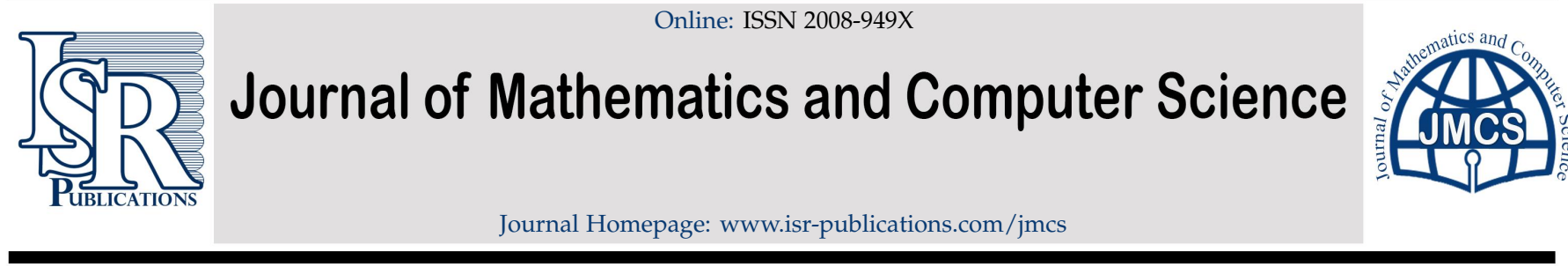

\title{
On upper and lower generalized semi-continuous fuzzy multifunctions
}

\author{
I. M. Taha \\ Department of Basic Sciences, Higher Institute of Engineering and Technology, Menoufia, Egypt. \\ Department of Mathematics, Faculty of Science, Sohag University, Egypt.
}

\begin{abstract}
In this paper, the concepts of upper and lower generalized continuous (resp. semi-generalized continuous and generalized semi-continuous) fuzzy multifunctions are defined where the domain of these multifunctions is a classical topological space with their values as arbitrary fuzzy sets in a fuzzy topological space. Main properties of these multifunctions along with their mutual relationships are discussed with the help of examples. Also, a new approach to these multifunctions between two fuzzy topological spaces $(X, \tau)$ and $(Y, \eta)$ based on the sense of Šostak are introduced. Some properties of these multifunctions along with their mutual relationships are investigated with the help of examples.
\end{abstract}

Keywords: General topology, fuzzy topology, fuzzy multifunctions, lower and upper generalized continuity (resp. semi-generalized continuity and generalized semi-continuity).

2020 MSC: 54A40, 54C08, 54C60.

(C)2022 All rights reserved.

\section{Introduction and preliminaries}

The theory of fuzzy sets provides a framework for mathematical modeling of those real world situations, which involve an element of uncertainty, imprecision, or vagueness in their description. Since its inception thirty years ago by Zadeh [25], this theory has found wide applications in information sciences, economics, engineering, etc.; for details the reader is referred to [17, 26].

A fuzzy multifunction or multi-valued mapping is a fuzzy set valued function [5, 19, 23, 24]. Fuzzy multifunctions arise in many applications, for instance, the budget multifunction occurs in decision theory, artificial intelligence and economic theory. The biggest difference between fuzzy functions and fuzzy multifunctions has to do with the definition of an inverse image, for a fuzzy multifunction there are two types of inverses. These two definitions of the inverse then leads to two definitions of continuity; for more details the reader is referred to [1-3, 14, 15, 20, 22]. Al-shami [6-8], introduced a new generalization of open sets and studied more notions via somewhere dense sets.

In this study, we introduce and study the notions of lower and upper generalized continuous (resp. semi-generalized continuous and generalized semi-continuous) fuzzy multifunctions in view of Šostak's

Email address: imtaha2010@yahoo.com (I. M. Taha)

doi: $10.22436 /$ jmcs.025.03.04

Received: 2021-03-03 Revised: 2021-03-15 Accepted: 2021-05-26 
sense. Also, we discuss the relations of these multifunctions with each other with the help of examples. Throughout this study, $X$ refers to an initial universe. The family of all fuzzy sets in $X$ is denoted by $\mathrm{I}^{X}$ and for $\lambda \in I^{X}, \lambda^{c}(x)=1-\lambda(x)$ for all $x \in X$ (where $I=[0,1]$ and $\left.I_{\circ}=(0,1]\right)$. For $t \in I, \underline{t}(x)=t$ for all $x \in X$. All other concepts are standard concepts of fuzzy set theory.

Let $A$ be a subset of an ordinary topological space $(X, T)$. $A$ is said to be generalized closed (resp.

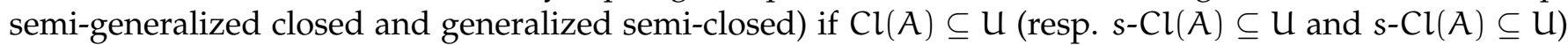
whenever $A \subseteq U$ and $U \in T$ (resp. $U \in S O(X)$ and $U \in T)[9,10,12,13]$. The complement of generalized closed (resp. semi-generalized closed and generalized semi-closed) set is called generalized open (resp. semi-generalized open and generalized semi-open). We denote $\mathrm{g}-\mathrm{Cl}(\mathrm{A})=\bigcap\{\mathrm{K}: \mathrm{A} \subseteq$ $K, K$ is generalized closed $\}, g-\operatorname{Int}(A)=\bigcup\{W: W \subseteq A, W$ is generalized open $\}, \operatorname{sg}-\mathrm{Cl}(A)=\bigcap\{\mathrm{K}: A \subseteq$ $K, K$ is semi-generalized closed $\}, \operatorname{sg}-\operatorname{Int}(A)=\bigcup\{W: W \subseteq A, W$ is semi-generalized open $\}, \operatorname{gs}-\operatorname{Cl}(A)=$ $\bigcap\{K: A \subseteq K, K$ is generalized semi-closed $\}$, and $g s-\operatorname{Int}(A)=\bigcup\{W: W \subseteq A, W$ is generalized semi-open $\}$, $[9,10,12,13]$. A topological space $(X, T)$ is called $T_{\frac{1}{2}}$ (resp. semi- $\left.T_{\frac{1}{2}}\right)[13]$ if $A^{c} \in T$ for each $A \subseteq X$ is generalized closed (resp. generalized semi-closed) set.

Let $(X, T)$ be a topological space in the classical sense and $(Y, \tau)$ be a fuzzy topological space in Šostak's sense. By $F:(X, T) \multimap(Y, \tau)$ we mean that $F$ is a fuzzy multifunction between $X$ and $Y$. For a fuzzy multifunction $F: X \multimap Y$, the upper inverse $F^{\oplus}(\mu)$ and lower inverse $F^{\ominus}(\mu)$ of $\mu \in I^{Y}$ are defined as follows: $F^{\oplus}(\mu)=\{x \in X: F(x) \leqslant \mu\}$ and $F^{\ominus}(\mu)=\{x \in X: F(x) q \mu\}$, also, $F^{\ominus}\left(\mu^{\mathcal{c}}\right)=X-F^{\oplus}(\mu)$ for each $\mu \in I^{Y}$ [18]. A fuzzy multifunction $F:(X, T) \multimap(Y, \tau)$ is called upper (resp. lower) semi-continuous [20] at a point $x_{\circ} \in X$ if $x_{\circ} \in F^{\oplus}(\mu)$ (resp. $x_{\circ} \in F^{\ominus}(\mu)$ ) for each $\mu \in I^{Y}$ with $\tau(\mu) \geqslant r$ and $r \in I_{0}$, there exists $\mathrm{U} \in \mathrm{T}$ and $\mathrm{x}_{\circ} \in \mathrm{U}$ such that $\mathrm{U} \subseteq \mathrm{F}^{\oplus}(\mu)$ (resp. $\mathrm{U} \subseteq \mathrm{F}^{\ominus}(\mu)$ ).

Let $(X, \tau)$ be a fuzzy topological space in Šostak sense [21], the interior and the closure of any fuzzy set $\lambda \in \mathrm{I}^{\mathrm{X}}$ denoted by $\mathrm{I}_{\tau}(\lambda, r)$ and $\mathrm{C}_{\tau}(\lambda, r)$. A mapping $F: X \multimap Y$ is called a fuzzy multifunction [11] if $F(x) \in I^{Y}$ for each $x \in X$. The degree of membership of $y$ in $F(x)$ is denoted by $F(x)(y)=G_{F}(x, y)$ for any $(x, y) \in X \times Y$. Also, $F$ is Crisp if $G_{F}(x, y)=1$ for each $x \in X, y \in Y$ and $F$ is Normalized if for each $x \in X$, there exists $y_{0} \in Y$ such that $G_{F}\left(x, y_{0}\right)=1$. The image $F(\lambda)$ of $\lambda \in I^{X}$, the lower inverse $F^{l}(\mu)$ and the upper inverse $F^{u}(\mu)$ of $\mu \in I^{Y}$ are defined as follows: $F(\lambda)(y)=V_{x \in X}\left[G_{F}(x, y) \wedge \lambda(x)\right]$, $F^{l}(\mu)(x)=\bigvee_{y \in Y}\left[G_{F}(x, y) \wedge \mu(y)\right]$ and $F^{u}(\mu)(x)=\bigwedge_{y \in Y}\left[G_{F}^{c}(x, y) \vee \mu(y)\right]$. All definitions and properties of image, upper and lower are found in [1].

\section{On upper and lower generalized semi-continuity}

In this section, the concepts of upper and lower generalized continuous (resp. semi-generalized continuous and generalized semi-continuous) fuzzy multifunctions are defined where the domain of these multifunctions is a classical topological space with their values as arbitrary fuzzy sets in a fuzzy topological space. Also, some properties of these multifunctions along with their mutual relationships are discussed with the help of examples.

Definition 2.1. A fuzzy multifunction $F:(X, T) \multimap(Y, \tau)$ is called:

(1) upper generalized continuous (resp. semi-generalized continuous and generalized semi-continuous) at a point $x_{\circ} \in X$ if $x_{\circ} \in F^{\oplus}(\mu)$ for each $\mu \in I^{Y}$ with $\tau(\mu) \geqslant r$ and $r \in I_{0}$, there exists generalized open (resp. semi-generalized open and generalized semi-open) set $\mathrm{U} \subseteq \mathrm{X}$ and $x_{\circ} \in \mathrm{U}$ such that $\mathrm{U} \subseteq \mathrm{F}^{\oplus}(\mu)$;

(2) lower generalized continuous (resp. semi-generalized continuous and generalized semi-continuous) at a point $x_{\circ} \in X$ if $x_{\circ} \in F^{\ominus}(\mu)$ for each $\mu \in I^{Y}$ with $\tau(\mu) \geqslant r$ and $r \in I_{0}$, there exists generalized open (resp. semi-generalized open and generalized semi-open) set $\mathrm{U} \subseteq \mathrm{X}$ and $x_{\circ} \in \mathrm{U}$ such that $\mathrm{U} \subseteq \mathrm{F}^{\ominus}(\mu)$;

(3) upper (resp. lower) generalized continuous, upper (resp. lower) semi-generalized continuous and upper (resp. lower) generalized semi-continuous if it is upper (resp. lower) generalized continuous, upper (resp. lower) semi-generalized continuous and upper (resp. lower) generalized semi-continuous at every $x_{\circ} \in X$. 
Remark 2.2.

(i) Upper (resp. lower) generalized continuity and upper (resp. lower) semi-generalized continuity are independent notions as shown by Problems 2.3 and 2.4.

(ii) Upper (resp. lower) semi-continuity [20] $\Rightarrow$ upper (resp. lower) generalized continuity $\Rightarrow$ upper (resp. lower) generalized semi-continuity.

(iii) Upper (resp. lower) semi-continuity [20] $\Rightarrow$ upper (resp. lower) semi-generalized continuity $\Rightarrow$ upper (resp. lower) generalized semi-continuity.

Problem 2.3. Let $X=\{a, b, c\}, T=\{X, \phi,\{a\}\}$ be an ordinary topology on $X$ and $Y=I$. Define fuzzy topology $\tau: \mathrm{I}^{\mathrm{Y}} \rightarrow \mathrm{I}$ as follows:

$$
\tau(\lambda)= \begin{cases}1, & \text { if } \lambda \in\{\underline{0}, \underline{1}\} \\ \frac{1}{2}, & \text { if } \lambda=\underline{0.3} \\ 0, & \text { otherwise. }\end{cases}
$$

Then,

(1) for $0<r \leqslant 0.3$, a fuzzy multifunction $F:(X, T) \multimap(Y, \tau)$ which is defined by: $F(a)=\underline{0.2}, F(b)=\underline{0.5}$, $F(c)=\underline{0.9}$, is lower generalized continuous and lower generalized semi-continuous but not lower semi-generalized continuous;

(2) for $0<r \leqslant 0.3$, a fuzzy multifunction $F:(X, T) \multimap(Y, \tau)$ which is defined by: $F(a)=\underline{0.2}, F(b)=\underline{0.5}$, $F(c)=\underline{0.9}$, is lower generalized continuous but not lower semi-continuous.

Problem 2.4. Let $X=\{a, b, c, d\}, T=\{X, \phi,\{a, b\},\{d\},\{a, b, d\}\}$ be an ordinary topology on $X$ and $Y=I$. Define fuzzy topology $\tau: I^{Y} \rightarrow$ I as follows:

$$
\tau(\lambda)= \begin{cases}1, & \text { if } \lambda \in\{\underline{0}, \underline{1}\} \\ \frac{2}{3}, & \text { if } \lambda=\underline{0.5} \\ 0, & \text { otherwise }\end{cases}
$$

Then,

(1) for $0<r \leqslant 0.5$, a fuzzy multifunction $F:(X, T) \multimap(Y, \tau)$, which is defined by: $F(a)=0.8, F(b)=0.4$, $\mathrm{F}(\mathrm{c})=\underline{0.9}, \mathrm{~F}(\mathrm{~d})=\underline{0.7}$, is lower semi-generalized continuous and lower generalized semi-continuous but not lower generalized continuous;

(2) for $0<r \leqslant 0.5$, a fuzzy multifunction $F:(X, T) \multimap(Y, \tau)$, which defined by: $F(a)=\underline{0.8}, F(b)=\underline{0.4}$, $\mathrm{F}(\mathrm{c})=\underline{0.9}, \mathrm{~F}(\mathrm{~d})=\underline{0.7}$, is lower semi-generalized continuous but not lower semi-continuous.

Theorem 2.5. A fuzzy multifunction $\mathrm{F}:(\mathrm{X}, \mathrm{T}) \multimap(\mathrm{Y}, \tau)$ is lower generalized continuous if $\mathrm{F}^{\ominus}(\mu)\left(\right.$ resp. $\left.\mathrm{F}^{\oplus}(\mu)\right)$ is generalized open (resp. generalized closed) set for each $\mu \in \mathrm{I}^{\mathrm{Y}}$ with $\tau(\mu) \geqslant r\left(\right.$ resp. $\mu \in \mathrm{I}^{\mathrm{Y}}$ with $\left.\tau\left(\mu^{\mathrm{c}}\right) \geqslant r\right)$.

Proof. Let $x_{\circ} \in X, \mu \in I^{Y}$ with $\tau(\mu) \geqslant r$ and $x_{\circ} \in F^{\ominus}(\mu)$. Then, $F^{\ominus}(\mu)$ is generalized open set. Thus, $F$ is lower generalized continuous. Other case it is easily proved from $F^{\oplus}\left(\mu^{c}\right)=X-F^{\ominus}(\mu)$.

The following theorems are similarly proved as in Theorem 2.5.

Theorem 2.6. A fuzzy multifunction $\mathrm{F}:(\mathrm{X}, \mathrm{T}) \multimap(\mathrm{Y}, \tau)$ is upper generalized continuous if $\mathrm{F}^{\oplus}(\mu)\left(\right.$ resp. $\left.\mathrm{F}^{\ominus}(\mu)\right)$ is generalized open (resp. generalized closed) set for each $\mu \in \mathrm{I}^{\mathrm{Y}}$ with $\tau(\mu) \geqslant r\left(\right.$ resp. $\mu \in \mathrm{I}^{\mathrm{Y}}$ with $\tau\left(\mu^{\mathrm{c}}\right) \geqslant r$ ).

Theorem 2.7. A fuzzy multifunction $\mathrm{F}:(\mathrm{X}, \mathrm{T}) \multimap(\mathrm{Y}, \tau)$ is lower semi-generalized continuous if $\mathrm{F}^{\ominus}(\mu)($ resp. $\mathrm{F}^{\oplus}(\mu)$ ) is semi-generalized open (resp. semi-generalized closed) set for each $\mu \in \mathrm{I}^{\mathrm{Y}}$ with $\tau(\mu) \geqslant \mathrm{r}$ (resp. $\mu \in \mathrm{I}^{\mathrm{Y}}$ with $\left.\tau\left(\mu^{c}\right) \geqslant r\right)$.

Theorem 2.8. A fuzzy multifunction $\mathrm{F}:(\mathrm{X}, \mathrm{T}) \multimap(\mathrm{Y}, \tau)$ is upper semi-generalized continuous if $\mathrm{F}^{\oplus}(\mu)$ (resp. $\mathrm{F}^{\ominus}(\mu)$ ) is semi-generalized open (resp. semi-generalized closed) set for each $\mu \in \mathrm{I}^{\gamma}$ with $\tau(\mu) \geqslant r$ (resp. $\mu \in \mathrm{I}^{Y}$ with $\left.\tau\left(\mu^{c}\right) \geqslant r\right)$. 
Theorem 2.9. A fuzzy multifunction $\mathrm{F}:(\mathrm{X}, \mathrm{T}) \multimap(\mathrm{Y}, \tau)$ is lower generalized semi-continuous if $\mathrm{F}^{\ominus}(\mu)$ (resp. $\mathrm{F}^{\oplus}(\mu)$ ) is generalized semi-open (resp. generalized semi-closed) set for each $\mu \in \mathrm{I}^{\mathrm{Y}}$ with $\tau(\mu) \geqslant \mathrm{r}$ (resp. $\mu \in \mathrm{I}^{\mathrm{Y}}$ with $\left.\tau\left(\mu^{\mathfrak{c}}\right) \geqslant r\right)$.

Theorem 2.10. A fuzzy multifunction $\mathrm{F}:(\mathrm{X}, \mathrm{T}) \multimap(\mathrm{Y}, \tau)$ is upper generalized semi-continuous if $\mathrm{F}^{\oplus}(\mu)$ (resp. $\mathrm{F}^{\ominus}(\mu)$ ) is generalized semi-open (resp. generalized semi-closed) set for each $\mu \in \mathrm{I}^{Y}$ with $\tau(\mu) \geqslant \mathrm{r}$ (resp. $\mu \in \mathrm{I}^{\mathrm{Y}}$ with $\left.\tau\left(\mu^{c}\right) \geqslant r\right)$.

Theorem 2.11. Let $(\mathrm{Y}, \tau)$ be a fuzzy topological space and $(\mathrm{X}, \mathrm{T})$ be a topological space satisfying the condition: for $A \subseteq X, \mu \in I^{Y}$ and $r \in I_{\circ}$,

(g) if $A=g-\operatorname{Int}(A)$ implies $A$ is generalized open set.

Then, $\mathrm{F}:(\mathrm{X}, \mathrm{T}) \multimap(\mathrm{Y}, \tau)$ is lower generalized continuous if one of the following statements is hold:

(1) $\mathrm{F}(\mathrm{g}-\mathrm{Cl}(\mathrm{A})) \leqslant \mathrm{C}_{\tau}(\mathrm{F}(\mathrm{A}), \mathrm{r})$;

(2) $g-C l\left(F^{\oplus}(\mu)\right) \leqslant F^{\oplus}\left(C_{\tau}(\mu, r)\right)$;

(3) $F^{\ominus}\left(I_{\tau}(\mu, r)\right) \leqslant g-\operatorname{Int}\left(F^{\ominus}(\mu)\right)$.

Proof.

$(1) \Rightarrow$ (2) For each $\mu \in I^{Y}$ and $r \in I_{\circ}$, let $A=F^{\oplus}(\mu)$. Then by (1),

$$
\left.\mathrm{F}\left(\mathrm{g}-\mathrm{Cl}\left(\mathrm{F}^{\oplus}(\mu)\right)\right) \leqslant \mathrm{C}_{\tau}\left(\mathrm{F}_{\left(\mathrm{F}^{\oplus}\right.}(\mu)\right), r\right) \leqslant \mathrm{C}_{\tau}(\mu, r) .
$$

Hence, we obtain $\mathrm{g}-\mathrm{Cl}\left(\mathrm{F}^{\oplus}(\mu)\right) \leqslant \mathrm{F}^{\oplus}\left(\mathrm{C}_{\tau}(\mu, r)\right)$.

$(2) \Rightarrow(3)$ Let $\mu \in I^{\gamma}$. Then by (2), $X-g-\operatorname{Int}\left(F^{\ominus}(\mu)\right)=g-C l\left(X-F^{\ominus}(\mu)\right)=g-C l\left(F^{\oplus}\left(\mu^{c}\right)\right) \leqslant F^{\oplus}\left(C_{\tau}\left(\mu^{c}, r\right)\right)=$ $\left[\mathrm{F}^{\ominus}\left(\mathrm{I}_{\tau}(\mu, r)\right)\right]^{\mathrm{c}}$. Thus, we obtain $\mathrm{F}^{\ominus}\left(\mathrm{I}_{\tau}(\mu, r)\right) \leqslant g-\operatorname{Int}\left(\mathrm{F}^{\ominus}(\mu)\right)$.

Suppose that (3) holds. Let $\mu \in \mathrm{I}^{\gamma}$ with $\eta(\mu) \geqslant r$. Then by (3), $F^{\ominus}(\mu) \leqslant g-\operatorname{Int}\left(F^{\ominus}(\mu)\right)$ and by $(g), F^{\ominus}(\mu)$ is generalized open set. Thus, $\mathrm{F}$ is lower generalized continuous.

The following theorems are similarly proved as in Theorem 2.11.

Theorem 2.12. Let $(\mathrm{Y}, \tau)$ be a fuzzy topological space and $(\mathrm{X}, \mathrm{T})$ be a topological space satisfying the condition: for $A \subseteq X, \mu \in I^{Y}$ and $r \in I_{\circ}$,

(sg) if $\mathrm{A}=\mathrm{sg}-\operatorname{Int}(\mathrm{A})$ implies $\mathrm{A}$ is semi-generalized open set.

Then, $\mathrm{F}:(\mathrm{X}, \mathrm{T}) \multimap(\mathrm{Y}, \tau)$ is lower semi-generalized continuous if one of the following statements is hold:

(1) $\mathrm{F}(\mathrm{sg}-\mathrm{Cl}(\mathrm{A})) \leqslant \mathrm{C}_{\tau}(\mathrm{F}(\mathrm{A}), \mathrm{r})$;

(2) $s g-C l\left(F^{\oplus}(\mu)\right) \leqslant F^{\oplus}\left(C_{\tau}(\mu, r)\right)$;

(3) $\mathrm{F}^{\ominus}\left(\mathrm{I}_{\tau}(\mu, r)\right) \leqslant s g-\operatorname{Int}\left(\mathrm{F}^{\ominus}(\mu)\right)$.

Theorem 2.13. Let $(\mathrm{Y}, \tau)$ be a fuzzy topological space and $(\mathrm{X}, \mathrm{T})$ be a topological space satisfying the condition: for $A \subseteq X, \mu \in I^{Y}$ and $r \in I_{\circ}$,

(gs) if $\mathrm{A}=\mathrm{gs}-\operatorname{Int}(\mathrm{A})$ implies $\mathrm{A}$ is generalized semi-open set.

Then, $\mathrm{F}:(\mathrm{X}, \mathrm{T}) \multimap(\mathrm{Y}, \tau)$ is lower generalized semi-continuous if one of the following statements is hold:

(1) $\mathrm{F}(\mathrm{gs}-\mathrm{Cl}(\mathrm{A})) \leqslant \mathrm{C}_{\tau}(\mathrm{F}(\mathrm{A}), \mathrm{r})$;

(2) $\operatorname{gs}-\mathrm{Cl}\left(\mathrm{F}^{\oplus}(\mu)\right) \leqslant \mathrm{F}^{\oplus}\left(\mathrm{C}_{\tau}(\mu, r)\right)$;

(3) $\mathrm{F}^{\ominus}\left(\mathrm{I}_{\tau}(\mu, r)\right) \leqslant g s-\operatorname{Int}\left(\mathrm{F}^{\ominus}(\mu)\right)$.

Corollary 2.14. Let $\mathrm{F}:(\mathrm{X}, \mathrm{T}) \multimap(\mathrm{Y}, \tau)$ be a fuzzy multifunction. Then if $(\mathrm{X}, \mathrm{T})$ is semi- $\mathrm{T}_{\frac{1}{2}}$ [13], the concepts of upper (resp. lower) semi-continuity, upper (resp. lower) generalized continuity, upper (resp. lower) semi-generalized continuity, and upper (resp. lower) generalized semi-continuity are equivalent. 


\section{A new approach to upper and lower generalized semi-continuity}

In this section, the notions of lower and upper generalized continuous (resp. semi-generalized continuous and generalized semi-continuous) fuzzy multifunctions are introduced and studied in view of Šostak's sense. Also, the relations of these multifunctions with each other are discussed with the help of examples.

Definition 3.1. Let $F: X \multimap Y$ be a fuzzy multifunction between two fuzzy topological space's $(X, \tau)$ and $(Y, \eta)$, and $r \in I_{\circ}$. Then $F$ is called:

(1) fuzzy upper generalized continuous (resp. semi-generalized continuous and generalized semi-continuous) at a fuzzy point $x_{t} \in \operatorname{dom}(F)$ if $x_{t} \in F^{\mathcal{u}}(\mu)$ for each $\mu \in I^{\gamma}$ with $\eta(\mu) \geqslant r$ there exists r-generalized fuzzy open [16] (resp. r-semi-generalized fuzzy open and r-generalized fuzzy semi-open [4]) set $\lambda \in \mathrm{I}^{X}$ and $x_{t} \in \lambda$ such that $\lambda \wedge \operatorname{dom}(F) \leqslant F^{\mathfrak{u}}(\mu)$.

(2) fuzzy lower generalized continuous (resp. semi-generalized continuous and generalized semi-continuous) at a fuzzy point $x_{t} \in \operatorname{dom}(F)$ if $x_{t} \in \mathrm{Fl}^{l}(\mu)$ for each $\mu \in \mathrm{I}^{Y}$ with $\eta(\mu) \geqslant r$ there exists $r$-generalized fuzzy open (resp. $r$-semi-generalized fuzzy open and $r$-generalized fuzzy semiopen) set $\lambda \in \mathrm{I}^{\mathrm{X}}$ and $\mathrm{x}_{\mathrm{t}} \in \lambda$ such that $\lambda \leqslant \mathrm{F}^{\mathrm{l}}(\mu)$.

(3) fuzzy upper (resp. lower) generalized continuous, fuzzy upper (resp. lower) semi-generalized continuous and fuzzy upper (resp. lower) generalized semi-continuous if it is fuzzy upper (resp. lower) generalized continuous, fuzzy upper (resp. lower) semi-generalized continuous and fuzzy upper (resp. lower) generalized semi-continuous at every $x_{t} \in \operatorname{dom}(F)$.

\section{Remark 3.2.}

(i) If $\mathrm{F}$ is normalized, then $\mathrm{F}$ is fuzzy upper generalized continuous (resp. semi-generalized continuous and generalized semi-continuous) at a fuzzy point $x_{t} \in \operatorname{dom}(F)$ if $x_{t} \in F^{\mathfrak{u}}(\mu)$ for each $\mu \in I^{Y}$ with $\eta(\mu) \geqslant r$ there exists $r$-generalized fuzzy open (resp. $r$-semi-generalized fuzzy open and $r$ generalized fuzzy semi-open) set $\lambda \in \mathrm{I}^{\mathrm{X}}$ and $x_{\mathrm{t}} \in \lambda$ such that $\lambda \leqslant \mathrm{F}^{\mathfrak{u}}(\mu)$.

(ii) Fuzzy upper (resp. lower) generalized continuity and fuzzy upper (resp. lower) semi-generalized continuity are independent notions as shown by Problems 3.3 and 3.4.

(iii) Fuzzy upper (resp. lower) semi-continuity [1] $\Rightarrow$ fuzzy upper (resp. lower) generalized continuity $\Rightarrow$ fuzzy upper (resp. lower) generalized semi-continuity.

(iv) Fuzzy upper (resp. lower) $\alpha$-continuity [14] $\Rightarrow$ fuzzy upper (resp. lower) semi-generalized continuity $\Rightarrow$ fuzzy upper (resp. lower) generalized semi-continuity.

Problem 3.3. Let $X=\left\{x_{1}, x_{2}\right\}, Y=\left\{y_{1}, y_{2}, y_{3}\right\}$ and $F: X \multimap Y$ be a fuzzy multifunction defined by: $\mathrm{G}_{\mathrm{F}}\left(\mathrm{x}_{1}, \mathrm{y}_{1}\right)=0.2, \mathrm{G}_{\mathrm{F}}\left(\mathrm{x}_{1}, \mathrm{y}_{2}\right)=0.8, \mathrm{G}_{\mathrm{F}}\left(\mathrm{x}_{1}, \mathrm{y}_{3}\right)=0.2, \mathrm{G}_{\mathrm{F}}\left(\mathrm{x}_{2}, \mathrm{y}_{1}\right)=0.5, \mathrm{G}_{\mathrm{F}}\left(\mathrm{x}_{2}, \mathrm{y}_{2}\right)=0.3$, and $\mathrm{G}_{\mathrm{F}}\left(\mathrm{x}_{2}, \mathrm{y}_{3}\right)=$ 0.9. Define $\rho \in \mathrm{I}^{\mathrm{X}}$ and $v \in \mathrm{I}^{Y}$ as follows: $v\left(\mathrm{y}_{1}\right)=0.8, v\left(\mathrm{y}_{2}\right)=0.8, v\left(\mathrm{y}_{3}\right)=0.6, \rho\left(x_{1}\right)=0.8, \rho\left(x_{2}\right)=0.6$. Define fuzzy topologies $\tau: \mathrm{I}^{\mathrm{X}} \rightarrow \mathrm{I}$ and $\eta: \mathrm{I}^{Y} \rightarrow \mathrm{I}$ as follows:

$$
\tau(\lambda)= \begin{cases}1, & \text { if } \lambda \in\{\underline{0}, \underline{1}\}, \\
\frac{1}{2}, & \text { if } \lambda \in\{\underline{0.1}, \underline{0.3}\}, \quad \eta(\mu)=\left\{\begin{array}{ll}
1, & \text { if } \mu \in\{\underline{0}, \underline{1}\}, \\
0, & \text { otherwise, }
\end{array}, \quad \text { if } \mu=v,\right. \\
0, & \text { otherwise. }\end{cases}
$$

Then,

(1) $F:(X, \tau) \multimap(Y, \eta)$ is fuzzy lower (resp. upper) generalized continuous but not fuzzy lower (resp. upper) semi-generalized continuous;

(2) $F:(X, \tau) \multimap(Y, \eta)$ is fuzzy lower (resp. upper) generalized semi-continuous but not fuzzy lower (resp. upper) semi-generalized continuous;

(3) $F:(X, \tau) \multimap(Y, \eta)$ is fuzzy lower (resp. upper) generalized continuous but not fuzzy lower (resp. upper) semi-continuous. 
Problem 3.4. Let $X=\left\{x_{1}, x_{2}\right\}, Y=\left\{y_{1}, y_{2}, y_{3}\right\}$ and $F: X \multimap Y$ be a fuzzy multifunction defined by $\mathrm{G}_{\mathrm{F}}\left(\mathrm{x}_{1}, \mathrm{y}_{1}\right)=0.2, \mathrm{G}_{\mathrm{F}}\left(\mathrm{x}_{1}, \mathrm{y}_{2}\right)=0.8, \mathrm{G}_{\mathrm{F}}\left(\mathrm{x}_{1}, \mathrm{y}_{3}\right)=0.3, \mathrm{G}_{\mathrm{F}}\left(\mathrm{x}_{2}, \mathrm{y}_{1}\right)=0.5, \mathrm{G}_{\mathrm{F}}\left(\mathrm{x}_{2}, \mathrm{y}_{2}\right)=0.3$, and $\mathrm{G}_{\mathrm{F}}\left(\mathrm{x}_{2}, \mathrm{y}_{3}\right)=0.7$. Define fuzzy topologies $\tau: \mathrm{I}^{\mathrm{X}} \rightarrow \mathrm{I}$ and $\eta: \mathrm{I}^{Y} \rightarrow$ I as follows:

$$
\tau(\lambda)=\left\{\begin{array}{ll}
1, & \text { if } \lambda \in\{\underline{0}, \underline{1}\}, \\
\frac{2}{3}, & \text { if } \lambda=\underline{0.4}, \\
0, & \text { otherwise, }
\end{array} \quad \eta(\mu)= \begin{cases}1, & \text { if } \mu \in\{\underline{0}, \underline{1}\} \\
\frac{2}{3}, & \text { if } \mu=\underline{0.65} \\
0, & \text { otherwise }\end{cases}\right.
$$

Then,

(1) $F:(X, \tau) \multimap(Y, \eta)$ is fuzzy lower (resp. upper) semi-generalized continuous but not fuzzy lower (resp. upper) generalized continuous;

(2) $F:(X, \tau) \multimap(Y, \eta)$ is fuzzy lower (resp. upper) generalized semi-continuous but not fuzzy lower (resp. upper) generalized continuous;

(3) $F:(X, \tau) \multimap(Y, \eta)$ is fuzzy lower (resp. upper) semi-generalized continuous but not fuzzy lower (resp. upper) $\alpha$-continuous.

Theorem 3.5. A fuzzy multifunction $\mathrm{F}:(\mathrm{X}, \tau) \multimap(\mathrm{Y}, \eta)$ is fuzzy lower generalized continuous if $\mathrm{F}^{\mathrm{l}}(\mu)$ (resp. $\mathrm{F}^{\mathfrak{u}}(\mu)$ ) is r-generalized fuzzy open (resp. $r$-generalized fuzzy closed) for each $\mu \in \mathrm{I}^{\gamma}$ with $\eta(\mu) \geqslant \mathrm{r}$ (resp. $\mu \in \mathrm{I}^{\mathrm{Y}}$ with $\left.\eta\left(\mu^{\mathfrak{c}}\right) \geqslant r\right), r \in I_{\circ}$.

Proof. Let $x_{t} \in \operatorname{dom}(F), \mu \in \mathrm{I}^{\gamma}$ with $\eta(\mu) \geqslant r$ and $x_{t} \in \mathrm{F}^{l}(\mu)$. Then, we have $\mathrm{F}^{\mathrm{l}}(\mu)$ is $r$-generalized fuzzy open. Thus, $F$ is fuzzy lower generalized continuous. Other case it is easily proved from $F^{\mathfrak{u}}\left(\mu^{c}\right)=\left(F^{l}(\mu)\right)^{c}$.

The following theorems are similarly proved as in Theorem 3.5.

Theorem 3.6. A normalized fuzzy multifunction $\mathrm{F}:(X, \tau) \multimap(\mathrm{Y}, \eta)$ is fuzzy upper generalized continuous if $\mathrm{F}^{\mathfrak{u}}(\mu)$ (resp. $\mathrm{F}^{\mathrm{l}}(\mu)$ ) is r-generalized fuzzy open (resp. $\mathrm{r}$-generalized fuzzy closed) set for each $\mu \in \mathrm{I}^{\mathrm{Y}}$ with $\eta(\mu) \geqslant \mathrm{r}$ (resp. $\mu \in \mathrm{I}^{\mathrm{Y}}$ with $\eta\left(\mu^{\mathrm{c}}\right) \geqslant \mathrm{r}$ ) and $\mathrm{r} \in \mathrm{I}_{\mathrm{o}}$.

Theorem 3.7. A fuzzy multifunction $\mathrm{F}:(\mathrm{X}, \tau) \multimap(\mathrm{Y}, \eta)$ is fuzzy lower semi-generalized continuous if $\mathrm{F}^{l}(\mu)$ (resp. $\mathrm{F}^{\mathfrak{u}}(\mu)$ ) is r-semi-generalized fuzzy open (resp. $\mathrm{r}$-semi-generalized fuzzy closed) set for each $\mu \in \mathrm{I}^{\mathrm{Y}}$ with $\eta(\mu) \geqslant \mathrm{r}$ (resp. $\mu \in \mathrm{I}^{\mathrm{Y}}$ with $\eta\left(\mu^{\mathrm{c}}\right) \geqslant \mathrm{r}$ ) and $\mathrm{r} \in \mathrm{I}_{\mathrm{o}}$.

Theorem 3.8. A normalized fuzzy multifunction $\mathrm{F}:(\mathrm{X}, \tau) \multimap(\mathrm{Y}, \eta)$ is fuzzy upper semi-generalized continuous if $\mathrm{F}^{\mathfrak{u}}(\mu)$ (resp. $\mathrm{F}^{\mathrm{l}}(\mu)$ ) is r-semi-generalized fuzzy open (resp. r-semi-generalized fuzzy closed) set for each $\mu \in \mathrm{I}^{\mathrm{Y}}$ with $\eta(\mu) \geqslant r\left(r e s p . \mu \in I^{Y}\right.$ with $\left.\eta\left(\mu^{c}\right) \geqslant r\right)$ and $r \in I_{0}$.

Theorem 3.9. A fuzzy multifunction $\mathrm{F}:(\mathrm{X}, \tau) \multimap(\mathrm{Y}, \eta)$ is fuzzy lower generalized semi-continuous if $\mathrm{F}^{\mathrm{l}}(\mu)$ (resp. $\mathrm{F}^{\mathfrak{u}}(\mu)$ ) is r-generalized fuzzy semi-open (resp. r-generalized fuzzy semi-closed) set for each $\mu \in \mathrm{I}^{\mathrm{Y}}$ with $\eta(\mu) \geqslant \mathrm{r}$ (resp. $\mu \in \mathrm{I}^{\mathrm{Y}}$ with $\eta\left(\mu^{\mathrm{c}}\right) \geqslant \mathrm{r}$ ) and $\mathrm{r} \in \mathrm{I}_{\mathrm{o}}$.

Theorem 3.10. A normalized fuzzy multifunction $\mathrm{F}:(\mathrm{X}, \tau) \multimap(\mathrm{Y}, \eta)$ is fuzzy upper generalized semi-continuous if $\mathrm{F}^{\mathfrak{u}}(\mu)$ (resp. $\mathrm{F}^{\mathrm{l}}(\mu)$ ) is r-generalized fuzzy semi-open (resp. r-generalized fuzzy semi-closed) set for each $\mu \in \mathrm{I}^{\mathrm{Y}}$ with $\eta(\mu) \geqslant r$ (resp. $\mu \in I^{Y}$ with $\left.\eta\left(\mu^{c}\right) \geqslant r\right)$ and $r \in I_{\circ}$.

Theorem 3.11. Let $(X, \tau)$ and $(\mathrm{Y}, \eta)$ be fuzzy topological spaces satisfying the condition:

(G) if $\lambda=\mathrm{GI}_{\tau}(\lambda, r)$ implies $\lambda$ is r-generalized fuzzy open for $\lambda \in \mathrm{I}^{\mathrm{X}}, \mu \in \mathrm{I}^{\mathrm{Y}}$ and $\mathrm{r} \in \mathrm{I}_{\circ}$.

Then, $\mathrm{F}:(\mathrm{X}, \tau) \multimap(\mathrm{Y}, \mathrm{\eta})$ is fuzzy lower generalized continuous if one of the following statements is hold:

(1) $F\left(G_{\tau}(\lambda, r)\right) \leqslant C_{\eta}(F(\lambda), r)$;

(2) $\mathrm{GC}_{\tau}\left(\mathrm{F}^{\mathfrak{u}}(\mu), r\right) \leqslant \mathrm{F}^{\mathfrak{u}}\left(\mathrm{C}_{\eta}(\mu, r)\right)$;

(3) $F^{l}\left(I_{\eta}(\mu, r)\right) \leqslant G I_{\tau}\left(F^{l}(\mu), r\right)$. 
Proof.

$(1) \Rightarrow(2)$ For each $\mu \in I^{Y}$ and $r \in I_{\circ}$, let $\lambda=F^{\mathcal{u}}(\mu)$. Then by $(1), F\left(G C_{\tau}\left(F^{\mathcal{u}}(\mu), r\right)\right) \leqslant C_{\eta}\left(F\left(F^{u}(\mu)\right), r\right) \leqslant$ $\mathrm{C}_{\eta}(\mu, r)$. Hence, we obtain $\mathrm{GC}_{\tau}\left(\mathrm{F}^{\mathfrak{u}}(\mu), r\right) \leqslant \mathrm{F}^{\mathfrak{u}}\left(\mathrm{C}_{\eta}(\mu, r)\right)$.

$(2) \Rightarrow(3)$ Let $\mu \in I^{Y}$. Then by (2), $\left[\mathrm{GI}_{\tau}\left(\mathrm{F}^{\mathrm{l}}(\mu), r\right)\right]^{\mathrm{c}}=\mathrm{GC}_{\tau}\left(\mathrm{F}^{\mathfrak{u}}\left(\mu^{\mathrm{c}}\right), r\right) \leqslant \mathrm{F}^{\mathfrak{u}}\left(\mathrm{C}_{\eta}\left(\mu^{\mathrm{c}}, r\right)\right)=\left[\mathrm{F}^{\mathrm{l}}\left(\mathrm{I}_{\eta}(\mu, r)\right)\right]^{\mathrm{c}}$. Hence, $\mathrm{Fl}^{\mathrm{l}}\left(\mathrm{I}_{\eta}(\mu, r)\right) \leqslant \mathrm{GI}_{\tau}\left(\mathrm{F}^{\mathrm{l}}(\mu), r\right)$.

Suppose that (3) holds. Let $\mu \in \mathrm{I}^{\gamma}$ with $\eta(\mu) \geqslant r$. Then by (3), $\mathrm{F}^{\mathrm{l}}(\mu) \leqslant \mathrm{GI}_{\tau}\left(\mathrm{F}^{\mathrm{l}}(\mu), \mathrm{r}\right)$ and by $(\mathrm{G}), \mathrm{F}^{\mathrm{l}}(\mu)$ is $r$-generalized fuzzy open. Thus, $F$ is fuzzy lower generalized continuous.

The following theorems are similarly proved as in Theorem 3.11.

Theorem 3.12. Let $(X, \tau)$ and $(\mathrm{Y}, \eta)$ be fuzzy topological spaces satisfying the condition:

(SG) if $\lambda=\operatorname{SGI}_{\tau}(\lambda, r)$ implies $\lambda$ is $r$-semi-generalized fuzzy open for $\lambda \in \mathrm{I}^{\mathrm{X}}, \mu \in \mathrm{I}^{\mathrm{Y}}$ and $\mathrm{r} \in \mathrm{I}_{\mathrm{o}}$.

Then, $\mathrm{F}:(\mathrm{X}, \tau) \multimap(\mathrm{Y}, \eta)$ is fuzzy lower semi-generalized continuous if one of the following is hold:

(1) $F\left(\operatorname{SGC}_{\tau}(\lambda, r)\right) \leqslant C_{\eta}(F(\lambda), r)$;

(2) $\operatorname{SGC}_{\tau}\left(\mathrm{F}^{\mathfrak{u}}(\mu), r\right) \leqslant \mathrm{F}^{\mathfrak{u}}\left(\mathrm{C}_{\eta}(\mu, r)\right)$;

(3) $\mathrm{Fl}^{\mathrm{l}}\left(\mathrm{I}_{\eta}(\mu, r)\right) \leqslant \operatorname{SGI}_{\tau}\left(\mathrm{Fl}^{\mathrm{l}}(\mu), r\right)$.

Theorem 3.13. Let $(\mathrm{X}, \tau)$ and $(\mathrm{Y}, \eta)$ be fuzzy topological space's satisfying the condition:

(GS) if $\lambda=\operatorname{GSI}_{\tau}(\lambda, r)$ implies $\lambda$ is $r$-generalized fuzzy semi-open for $\lambda \in \mathrm{I}^{\mathrm{X}}, \mu \in \mathrm{I}^{\gamma}$ and $\mathrm{r} \in \mathrm{I}_{\circ}$.

Then, $\mathrm{F}:(\mathrm{X}, \tau) \multimap(\mathrm{Y}, \eta)$ is fuzzy lower generalized semi-continuous if one of the following is hold:

(1) $\mathrm{F}\left(\mathrm{GSC}_{\tau}(\lambda, r)\right) \leqslant \mathrm{C}_{\eta}(\mathrm{F}(\lambda), r)$;

(2) $\operatorname{GSC}_{\tau}\left(\mathrm{F}^{\mathfrak{u}}(\mu), r\right) \leqslant \mathrm{F}^{\mathfrak{u}}\left(\mathrm{C}_{\eta}(\mu, r)\right)$;

(3) $F^{l}\left(I_{\eta}(\mu, r)\right) \leqslant \operatorname{GSI}_{\tau}\left(F^{l}(\mu), r\right)$.

Corollary 3.14. Let $\mathrm{F}: \mathrm{X} \multimap \mathrm{Y}, \mathrm{H}: \mathrm{Y} \multimap \mathrm{Z}$ be two fuzzy multifunction's and let $(\mathrm{X}, \tau),(\mathrm{Y}, \mathrm{\eta})$ and $(\mathrm{Z}, \delta)$ be three fuzzy topological spaces. Then we have,

(1) if $\mathrm{F}$ is fuzzy lower generalized continuous (resp. semi-generalized continuous and generalized semi-continuous) and $\mathrm{H}$ is fuzzy lower semi-continuous, then $\mathrm{H} \circ \mathrm{F}$ is fuzzy lower generalized continuous (resp. semi-generalized continuous and generalized semi-continuous);

(2) if $\mathrm{F}$ is normalized fuzzy upper generalized continuous (resp. semi-generalized continuous and generalized semicontinuous) and $\mathrm{H}$ is normalized fuzzy upper semi-continuous, then $\mathrm{H} \circ \mathrm{F}$ is fuzzy upper generalized continuous (resp. semi-generalized continuous and generalized semi-continuous).

Corollary 3.15. Let $\mathrm{F}:(\mathrm{X}, \tau) \multimap(\mathrm{Y}, \eta)$ be a fuzzy multifunction. Then if $(\mathrm{X}, \tau)$ is $\mathrm{r}-\mathrm{FST}_{\frac{1}{2}}$ [4], the concepts of fuzzy upper (resp. lower) semi-continuity, fuzzy upper (resp. lower) $\alpha$-continuity, fuzzy upper (resp. lower) generalized continuity, fuzzy upper (resp. lower) semi-generalized continuity, and fuzzy upper (resp. lower) generalized semicontinuity are equivalent.

\section{Conclusion}

In this article, we have continued to study the continuity of fuzzy multifunctions. First, we presented and studied the notions of upper and lower generalized continuous (resp. semi-generalized continuous and generalized semi-continuous) fuzzy multifunctions where the domain of these multifunctions is a classical topological space with their values as arbitrary fuzzy sets in fuzzy topological space in view of Šostak's sense. Second, a new approach to these multifunctions between two fuzzy topological spaces $(X, \tau),(Y, \eta)$ based on the sense of Šostak are introduced. Some properties of these multifunctions along with their mutual relationships are established with the help of examples. This paper, not only can form the theoretical basis for further applications of fuzzy multifunctions, but also lead to the development of other scientific areas. 


\section{Acknowledgment}

The author is grateful thanks to the referees for their valuable comments and suggestions which have improved this paper

\section{References}

[1] S. E. Abbas, M. A. Hebeshi, I. M. Taha, On fuzzy upper and lower semi-continuous multifunctions, J. Fuzzy Math., 22 (2014), 951-962. 1, iii

[2] S. E. Abbas, M. A. Hebeshi, I. M. Taha, On upper and lower almost weakly continuous fuzzy multifunctions, Iran. J. Fuzzy Syst., 12 (2015), 101-114.

[3] S. E. Abbas, M. A. Hebeshi, I. M. Taha, On fuzzy upper and lower ß-irresolute multifunctions, J. Fuzzy Math., 23 (2015), 171-187. 1

[4] S. E. Abbas, M. Taha, Semi-generalized continuous mappings in Šostak's fuzzy topological spaces, J. Fuzzy Math., 19 (2011), 643-664. 1, 3.15

[5] J. Albrycht, M. Matłoka, On fuzzy multivalued functions. I. Introduction and general properties, Fuzzy Sets and Systems, 12 (1984), 61-69. 1

[6] T. M. Al-shami, Somewhere dense sets and ST1-spaces, Punjab Univ. J. Math., 49 (2017), 101-111. 1

[7] T. M. Al-shami, Soft somewhere dense sets on soft topological spaces, Commun. Korean Math. Soc., 33 (2018), 13411356.

[8] T. M. Al-shami, T. Noiri, More notions and mappings via somewhere dense sets, Afr. Mat., 30 (2019), 1011-1024. 1

[9] S. P. Arya, T. M. Nour, Characterizations of s-normal spaces, Indian J. Pure Appl. Math., 21 (1990), 717-719. 1

[10] K. Balachandran, P. Sundaram, H. Maki, On generalized continuous maps in topological spaces, Mem. Fac. Sci. Kochi Univ. Ser. A Math., 12 (1991), 5-13. 1

[11] I. Beg, Continuity of fuzzy multifunctions, J. Appl. Math. Stochastic Anal., 12 (1999), 17-22. 1

[12] P. Bhattacharyya, B. K. Lahiri, Semi generalized closed sets in topology, Indian J. Math., 29 (1987), 375-382. 1

[13] W. Dunham, N. Levine, Further results on generalized closed sets in topology, Kyungpook Math. J., 20 (1980), 169-175. $1,2.14$

[14] M. A. Hebeshi, I. M. Taha, On upper and lower $\alpha$-continuous fuzzy multifunctions, J. Intell. Fuzzy Systems, 28 (2015), 2537-2546. 1, iv

[15] M. A. Hebeshi, I. M. Taha, On fuzzy upper and lower almost $\beta$-continuous multifunctions, J. Fuzzy Math., 24 (2016), 15-29. 1

[16] Y. C. Kim, J. W. Park, Some properties of r-generalized fuzzy closed sets, Far East J. Math. Sci., 7 (2002), 253-268. 1

[17] H. X. Li, V. C. Yen, Fuzzy sets and fuzzy decision-making, CRC Press, Boca Raton, (1995). 1

[18] M. N. Mukherjee, S. Malakar, On almost continuous and weakly continuous fuzzy multifunctions, Fuzzy Sets and Systems, 41 (1991), 113-125. 1

[19] N. S. Papageorgiou, Fuzzy topology and fuzzy multifunctions, J. Math. Anal. Appl., 109 (1985), 397-425. 1

[20] A. A. Ramadan, A. A. Abd El-latif, Fuzzy pairwise multifunctions, Asian J. Math. Comput. Res., 2 (2015), $219-234$. 1 , ii, iii

[21] A. P. Šostak, On a fuzzy topological structure, Rend. Circ. Mat. Palermo (2) Suppl., 11 (1985), 89-103. 1

[22] I. M. Taha, S. E. Abbas, A Study on fuzzy multifunctions in Šostak sense: To investigate more structure of fuzzy upper and fuzzy lower continuous multifunctions, Lambert Academic Publishing, Germany (2017). 1

[23] E. Tsiporkova-Hristoskova, B. De Baets, E. Kerre, A fuzzy inclusion based approach to upper inverse images under fuzzy multivalued mappings, Fuzzy Sets and Systems, 85 (1997), 93-108. 1

[24] E. Tsiporkova, B. De Baets, E. Kerre, Continuity of fuzzy multivalued mappings, Fuzzy Sets and Systems, 94 (1998), 335-348. 1

[25] L. A. Zadeh, Fuzzy sets, Information and Control, 8 (1965), 338-353. 1

[26] H.-J. Zimmermann, Fuzzy set theory—and its applications, Kluwer Academic Publishers, Boston, (1992). 1 